\title{
STUDI ANALISIS EFEKTIVITAS JEMBATAN \\ PENYEBERANGAN ORANG (JPO) \\ STUDI KASUS : JPO JL. SISINGAMANGARAJA \\ KOTA MEDAN
}

\author{
Johan Oberlyn Simanjuntak 1), \\ Tiurma Elita Saragi 2), \\ Nurvita Insani Simanjuntak 3), \\ Andri Setiawan Mendrofa ${ }^{4)}$ \\ Universitas HKBP Nommensen Medan 1,2,3,4) \\ E-mail : oberlyn.simanjuntak@yahoo.co.id ${ }^{1)}$ saragih 27@yahoo.com $^{2)}$ \\ nurvitainsani@gmail.com ${ }^{3}$ ) andrimendrofa4@gmail.com $^{4)}$
}

\begin{abstract}
The pedestrian bridge (JPO), as part of the supporting facilities for the road transportation system, has an important role in the arrangement of the transportation system because in its planning the pedestrian bridge is planned to meet safety, security and comfort aspects and can be a liaison between areas that can be accessed by pedestrians. The research was conducted at the Sisingamangaraja Stree JPO which connects two (2) commercial areas, namely the Grand Mosque and the Yuki Simpang Raya shopping center which are generally crowded with residents of Medan City. Primary data collection in the field is carried out on the number of road crossings, both using JPO or not. The data finally shows that the Sisingamangaraja Street JPO is a JPO that is considered Effective as indicated by the percentage value of effectiveness is $61 \%$. In addition, to show the correct crossing facilities on the road, traffic volume calculations are also carried out during peak hours which indicate that the correct crossing facility is a pelican with a waiting booth.
\end{abstract}

Keywords: effectiveness, pedestrian bridge, pedestrians

\begin{abstract}
ABSTRAK
Sebagai bagian dari fasilitas pendukung sistem transportasi jalan raya, Jembatan Penyeberangan Orang (JPO) mempunyai peran penting dalam tatanan system transportasi karena dalam perencanaannya jembatan penyeberangan direncanakan harus memenuhi aspek keselamatan, kemanan dan kenyamanan serta dapat menjadi penghubung antar kawasan yang dapat diakses oleh pejalan kaki. Penelitian dilakukan pada JPO Jalan Sisingamangaraja yang menjadi penghubung dua (2) kawasan komersil yaitu Mesjid Raya dan pusat perbelanjaan Yuki Simpang Raya yang pada umumnya ramai dikunjungi warga Kota Medan. Pengambilan data primer di lapangan dilakukan terhadap jumlah penyeberang ruas jalan baik yang menggunakaan JPO atau pun yang tidak menggunakan JPO. Data tersebut akhirnya menunjukkan bahwa JPO Jalan Sisingamangaraja merupakan JPO yang dinilai Efektif yang ditunjukkan dengan nilai persentase efektivitas adalah sebesar 61\%. Selain itu, untuk menunjukkan fasilitas penyeberangan yang tepat pada ruas jalan tersebut, perhitungan volume lalu lintas juga dilakukan pada jam sibuk yang menunjukkan bahwa fasilitas penyeberangan yang tepat adalah pelican dengan lapak tunggu.
\end{abstract}

\section{KataKunci : efektivitas,jembatan penyeberangan orang, pejalan kaki}

\section{PENDAHULUAN}

Sebagai derived demand (kebutuhan turunan), transportasi memegang peranan penting dalam tatanan kehidupan bermasyarakatm sebagai sarana dalam pemenuhan berbagai macam kebutuhan perjalanan. Dalam penyelenggaraannya khususnya sistem transportasi darat atau transportasi jalan raya menjadi satusatunya sistem transportasi yang sangat 
dekat dalam kehidupan masyarakat. Dalam Undang- Undang No.22 Tahun 2009 tentang Lalu Lintas dan Angkutan Jalan Pasal 3 Ayat 1, dinyatakan bahwa tujuan dari penyelenggaraan lalu lintas dan angkutan jalan adalah untuk mewujudkan pelayanan lalu lintas dan angkutan jalan yang aman, selamat, tertib, lancar dan terpadu dengan moda angkutan lain untuk mendorong perekonomian nasional, memajukan kesejahteraan umum, memperkukuh persatuan dan kesatuan bangsa, serta mampu menjunjung tinggi martabat bangsa.

Untuk mewujudkan tujuan lalu lintas dan angkutan jalan maka salah satu cara adalah dengan penyediaan sarana dan prasarana serta fasilitas pendukung dari pelaksanaan lalu lintas dan angkutan jalan tersebut. Dalam teorinya, fasilitas pendukung lalu lintas dan angkutan jalan adalah berupa trotoar, lajur sepeda, tempat penyeberangan pejalan kaki, halte dan/atau fasilitas khusus bagi penyandang cacat dan manusia usia lanjut.

Sebagai bagian dari sistem transportasi jalan raya, pejalan kaki juga turut mendapat bagian dalam sistem penyelenggaraan transportasi. Pemenuhan akan fasilitas pendukung pejalan kaki turut perlu mendapat pertimbangan dikarenakan masih tingginya jumlah pejalan kaki di Indonesia khususnya Kota Medan. Berdasarkan Pedoman Perencanaan Teknis Fasilitas Pejalan Kaki (PD 03-2017-B), prinsip perencanaan fasilitas pejalan kaki meliputi :

1. Memenuhi aspek keterpaduan sistem, dari penataan lingkungan, sistem transportasi dan aksesibilitas antar kawasan;

2. Memenuhi aspek kontinuitas, yaitu menghubungkan antara tempat asal ke tempat tujuan dan sebaliknya;

3. Memenuhi aspek keselamatan, kemanan dan kenyamanan;

4. Memenuhi aspek aksesibilitas, dimana fasilitas yang direncanakan harus dapat diakses oleh seluruh pengguna, termasuk oleh pengguna dengan berbagai keterbatasan fisik.

Pelaksanaan penelitian ini dilakukan guna mencapai tujuan untuk mengetahui berapa besar tingkat efektivitas dari Jembatan Penyeberangan Orang (JPO) Jalan Sisingamangaraja yang menjadi fasilitas pendukung sistem transportasi di Kota Medan. Penelitian ini juga diharapkan dapat menunjukkan fasilitas penyeberangan yang tepat sesuai dengan yang dianjurkan dalam Pedoman Perencanaan Teknis Fasilitas Pejalan Kaki (PD 03-2017-B) sehingga JPO Jalan Sisingamangaraja di masa mendatang dapat menjadi fasilitas pendukung sistem transportasi jalan raya yang dapat memenuhi kebutuhan pejalan kaki khususnya yang berada di sekitar lokasi JPO tersebut.

\section{TINJAUAN PUSTAKA}

\section{Penyeberangan Sebidang}

Penyeberangan sebidang pada umumnya dapat digunakan pada persimpangan ataupun pada ruas jalan. Penyeberangan sebidang dapat dibedakan menjadi 3 (tiga) yaitu penyeberangan zebra dan penyeberangan pelican dan pedestrian platform. Adapun perbedaan antara 
penyeberangan zebra dan penyeberangan pelican adalah sebagai berikut :

1) Penyeberangan zebra biasaya dipasang pada ruas jalan atau pada kaki persimpangan jalan yang dilengkapi atau tidak dilengkapi APILL sedangkan Penyeberangan pelican hanya dapat digunakan pada ruas jalan dengan jarak minimal 300 meter dari persimpangan.

2) Penyeberangan pelican digunakan dengan pada ruas jalan dengan kecepatan operasional rata-rata lalu lintas kendaraan adalah $>40 \mathrm{~km} / \mathrm{jam}$. Sedangkan pada penyeberangan zebra apabila diletakkan pada simpang dengan APILL, maka batas kecepatan kendaraan bermotor adalah $<40 \mathrm{~km} / \mathrm{jam}$.

Sedangkan pedestrian platfrom merupakan jalur pejalan kaki yang biasanya berupa fasilitas penyeberangan sebidang yang memiliki permukaan lebih tinggi dibandingkan dengan permukaan jalan. Pedestrian platform pada umumnya pasang di ruas jalan lokal, jalan kolektor serta bagian jalan yang digunakan sebagai tempat menurunkan ataupun menaikkan penumpang yang biasanya digunakan di bandara, pusat perbelajaan ataupun pusat pendidikan.

\section{Penyeberangan Tidak Sebidang}

Pada penggunaannya penyeberangan tidak sebidang terdiri atas 2 (dua) jenis penyeberangan yaitu :

1. Jembatan penyeberangan orang Syarat pelaksanaan pengadaan jembatan penyeberangan orang adalah sebagai berikut : a) lebar minimum 2 (dua) meter kelandaian tangga maksimum $20^{\circ}$;

b) Apabila diperuntukkan untuk pesepeda, maka lebar minimal adalah 2,75 meter;

c) Dilengkapi dengan pagar yang memadai;

d) Bagian tengah tangga dilengkapi dengan pelandaian untuk mendukung pengguna yang menggunakan kursi roda;

e) Lokasi dan bangunan jembatan harus sesuai dengan kebutuhan pejalan kaki dan estetika;

f) Penempatan jembatan tidak boleh mengurangi lebar efektif trotoar.

2. Terowongan

Syarat pelaksanaan pengadaan terowongan adalah sebagai berikut:

a) Dilengkapi dengan penerangan;

b) Desain dengan pertimbangan sistem aliran udara sesuai dengan kebutuhan;

c) Lebar minimal adalah 2,5 meter dan bila diperuntukkan bagi sepeda, maka lebar minimal adalah 2,75 meter;

d) Apabila terowongan menggunakan tangga, maka kelandaian tangga maksimal $20^{\circ}$;

e) Tinggi terendah minimal 3 Meter. Persyaratan dalam penentuan penggunaan penyeberangan tidak sebidang didasarkan pada beberapa hal berikut, antara lain :
1. Fasilitas
penyeberangan sebidang yang ada sudah mengganggu arus lalu lintas; 
2. Tingginya

frekuensi

kecelakaan lalu lintas yang melibatkan pejalan kaki;

3. Kecepataan rencana lalu lintas yang digunakan pada ruas jalan adalah 70 km/jam;

4. Pada lokasi ataupun kawasan strategis yang tidak memungkinkan penggunaan penyeberang jalan sebidang.

\section{Kriteria Penentuan Fasilitas Penyeberang Sebidang dan Tidak Sebidang}

Berdasarkan Pedoman Perencanaan Teknik Fasilitas Pejalan Kaki (PD 032017-B) yang dikeluarkan oleh Kementerian Pekerjaan Umum dan Perumahan Rakyat, bahwa adapun syarat dalam pemilihan penyeberangan sebidang dan tidak sebidang adalah didasarkan atas $\mathrm{P}$ yaitu arus pejalan kaki yang menyeberangi ruas jalan di bawah jembatan sepanjang 100 meter dalam 1 jam (orang/jam) dengan $\mathrm{V}$ yaitu arus lalu lintas dalam dua arah (kendaraan/jam) yang dirumuskan dalam persamaan PV2. Syaratkriteria penentuan fasilitas penyeberangan sebidang ditunjukkan pada Tabel 1 sedangkan kriteria penentuan fasilitas penyeberangan tidak sebidang ditunjukkan pada Tabel 2.

Tabel 1. Kriteria penentuan fasilitas penyeberangan sebidang

\begin{tabular}{|c|c|c|c|}
\hline $\begin{array}{c}\text { P } \\
\text { (org/jam) }\end{array}$ & $\begin{array}{c}\mathbf{V} \\
\text { (org/jam) }\end{array}$ & PV $^{2}$ & Rekomendasi \\
\hline $50-1100$ & $300-500$ & $>10^{8}$ & $\begin{array}{l}\text { Zebra cross } \\
\text { atau } \\
\text { pedestrian } \\
\text { platform* }\end{array}$ \\
\hline $50-1100$ & $400-750$ & $>2 \times 10^{8}$ & $\begin{array}{c}\text { Zebra cross } \\
\text { dengan } \\
\text { lapak }\end{array}$ \\
\hline
\end{tabular}

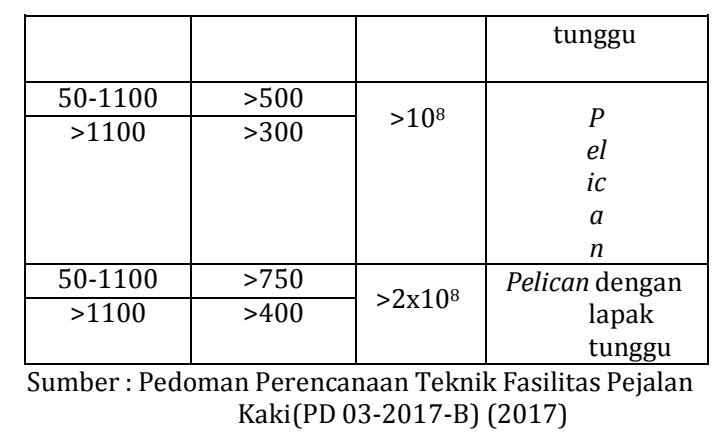

Tabel 2. Kriteria penentuan fasilitas penyeberangan sebidang

\begin{tabular}{|c|c|c|c|}
\hline $\begin{array}{c}\mathbf{P} \\
\text { (org/jam) }\end{array}$ & $\begin{array}{c}\mathbf{V} \\
\text { (org/jam) }\end{array}$ & $\mathbf{P V}^{\mathbf{2}}$ & Rekomendasi \\
\hline$>1100$ & $>750$ & $>2 \times 10^{8}$ & $\begin{array}{c}\text { Penyeberangan } \\
\text { tidak sebidang }\end{array}$ \\
\hline \multicolumn{3}{|c|}{ Sumber : Pedoman Perencanaan Teknik Fasilitas Pejalan } \\
\hline
\end{tabular}
Kaki(PD 03-2017-B) (2017)

dimana :

$\mathrm{P}=$ arus lalu lintas penyeberang pejalan kaki sepanjang 100 meter (orang/jam)

$\mathrm{V}=$ arus lalu lintas kendaraan dua arah perjam (kendaraan/jam)

\section{Pemilihan Lokasi Penyelenggaraan Jembatan Penyeberangan}

Dalam Tata Cara Perencanaan Jembatan Penyeberangan Untuk Pejalan Kaki Di Perkotaan No.027/Bt/1995 (1995), Perencanaan jembatan penyeberangan untuk pejalan kaki, pemilihan lokasi didasarkan pada beberapa hal berikut :

1. Jarak maksimum dari pusat kegiatan dan keramaian serta dari tempat pemberhentian bis adalah 50 meter

2. Jarak minimum dari persimpangan jalan adalah 50 meter

3. Jembatan harus mudah dilihat serta dapat dijangkau dengan mudah dan aman

\section{Tingkat Efektivitas Jembatan Penyeberangan \\ Menurut Hariman (2014),} efektivitas jembatan penyeberangan dapat dihitungdengan persamaan berikut :

$$
\begin{gathered}
E_{\text {fektivitas }} J P O=\frac{A}{B} \times 100 \% \\
\text { dimana : } \\
\mathrm{A}=\underset{\text { menggunakan }}{\text { Jumlah pejalan }} \quad \begin{array}{r}
\text { kaki yang } \\
\text { jembatan }
\end{array}
\end{gathered}
$$


penyeberangan

$\mathrm{B}=$ Total jumlah penjalan kaki yang menyeberangi ruas jalan tertentu

Tingkat efektivitas selanjutnya dapat di kategorikan menjadi 5 kategori seperti yang digambarkan pada Tabel 3. berikut.

Tabel 3. Klasifikasi EfektivitasJembatan Penyeberangan

\begin{tabular}{|c|c|}
\hline $\begin{array}{c}\text { Persentase } \\
(\mathbf{\% )}\end{array}$ & Tingkat Efektivitas \\
\hline $0-20$ & Sangat tidak efektif \\
\hline $21-40$ & Tidak efektif \\
\hline $41-60$ & Cukup efektif \\
\hline $61-80$ & Efektif \\
\hline $81-100$ & Sangat efektif \\
\hline
\end{tabular}

Sumber : Hariman (2014)

\section{METODE PELAKSANAAN}

Penelitian ini dilakukan dengan menggunakan data primer yaitu data yang didapatkan langsung di lapangan. Survei dilakukan 2 minggu pada ruas Jalan Sisingamangaraja yang dilengkapi dengan Jembatan Penyeberangan Orang yang terletak pada persimpangan Mesjid Raya Kota Medan.

\section{Survei Lalu Lintas dan Penyeberang Jalan} Survei lalu lintas dilakukan pada 2 waktu sibuk yang berbeda yaitu :

1. Jam sibuk siang pada pukul $11.30-$ 13.00WIB;

2. Jam sibuk sore pada pukul 16.30 18.00

Tabel 4. Hasil survei penyeberang jalan

\begin{tabular}{|c|c|c|c|}
\hline $\begin{array}{c}\text { Hari } \\
\text { ke- }\end{array}$ & $\begin{array}{c}\text { Pengguna } \\
\text { JPO }\end{array}$ & $\begin{array}{c}\text { Non } \\
\text { Pengguna } \\
\text { JPO }\end{array}$ & Jumlah \\
\hline \multicolumn{4}{|l|}{ Jam sibuk siang } \\
\hline 1 & 9 & 4 & 13 \\
\hline 2 & 18 & 14 & 32 \\
\hline 3 & 45 & 15 & 60 \\
\hline 4 & 32 & 18 & 50 \\
\hline 5 & 69 & 62 & 131 \\
\hline 6 & 90 & 78 & 168 \\
\hline 7 & 37 & 21 & 58 \\
\hline \multicolumn{5}{|l}{} \\
\hline Jam sibuk sore & 300 & 512 \\
\hline 1 & 98 & 55 & 153 \\
\hline 2 & 79 & 38 & 117 \\
\hline
\end{tabular}

\begin{tabular}{|c|c|c|c|}
\hline 3 & 63 & 36 & 99 \\
\hline 4 & 85 & 48 & 133 \\
\hline 5 & 68 & 45 & 113 \\
\hline 6 & 110 & 80 & 190 \\
\hline 7 & 80 & 53 & 133 \\
\hline & 583 & & 938 \\
\hline Total & $\mathbf{8 8 3}$ & & $\mathbf{1 4 5 0}$ \\
\hline
\end{tabular}

Sumber : Hasil penelitian(2021)

Dengan menggunakan persamaan efektivitas (Hariman, 2014) maka efektivitas penggunaan JPO Jalan Sisingamangaraja Kota Medan adalah sebagai berikut.

$$
E_{\text {fektivitas }} J P O=\frac{A}{B} \times 100 \%
$$

Sedangkan survei untuk penyeberangan jalan $E_{\text {fektivitas }} J P O=$ $\frac{883}{1450} \times 100 \%$ dilakukan pada pejalan kaki baik yang menggunakan JPO ataupun yang tidak menggunakan JPO pada jam yang sama dengan survei lalu lintas. Asumsi penentuan pengambilan jam sibuk siang, didasarkan bahwa JPO terletak pada Mesjid Raya yang pada umumnya akan mulai ramai didatangi pada siang hari menjelang sore hari. Hal ini juga dikaitkan dengan menggunakan mesjid sebagai tempat ibadah khususnya pada hari Jumat yang asumsinya bahwa akan banyak ditemukan pengguna JPO yang akan menuju mesjid.

\section{HASIL DAN PEMBAHASAN Analisis Efektivitas JPO}

Hasil survei lapangan terhadap penyeberang jalan baik pengguna JPO ataupun non pengguna JPO dijabarkan pada Tabel 4. berikut.

\section{Efektivitas JPO $=61 \%$}

Dari hasil analisis diperoleh nilai efektivitas adalah sebesar $61 \%$ maka tingkat efektivitas JPO Jalan Sisingamangaraja Kota Medan adalah efektif (61-80\%).

\section{Volume Lalu Lintas}

Hasil survei lapangan terhadap arus lalu lintas yang berada di bawah JPO Jalan Sisingamangaraja Kota Medan dijabarkan pada Tabel 5. berikut. 
Tabel 5. Volume lalu lintas (kendaraan/jam)

\begin{tabular}{|c|c|c|c|c|}
\hline $\begin{array}{c}\text { Hari } \\
\text { ke- }\end{array}$ & LV & HV & MC & Jumlah \\
\hline Jam sibuk siang \\
\hline 1 & 2375 & 151 & 4257 & 6783 \\
\hline 2 & 2014 & 144 & 3375 & 5533 \\
\hline 3 & 2237 & 160 & 4017 & 6414 \\
\hline 4 & 2177 & 145 & 4018 & 6340 \\
\hline 5 & 2704 & 161 & 4779 & 7644 \\
\hline 6 & 2643 & 199 & 4639 & 7481 \\
\hline 7 & 2171 & 114 & 3877 & 6162 \\
\hline Jam sibuk sore & 3095 & 153 & 5834 & 9082 \\
\hline 1 & 3027 & 165 & 5409 & 8601 \\
\hline 2 & 2962 & 193 & 6173 & 9328 \\
\hline 3 & 2724 & 180 & 5967 & 8871 \\
\hline 4 & 3265 & 170 & 6828 & 10263 \\
\hline 5 & 2673 & 214 & 5622 & 8509 \\
\hline 6 & 2724 & 167 & 4222 & 7113 \\
\hline 7 & \multicolumn{5}{|l}{} \\
\hline \multicolumn{4}{|l|}{ Sumb }
\end{tabular}

Sumber : Hasil penelitian(2021)

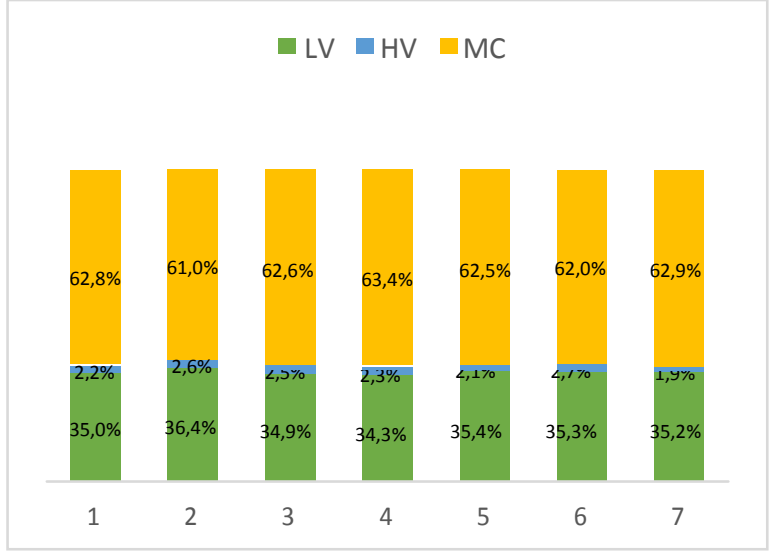

Gambar 1. Volume lalu lintasJam sibuk siang

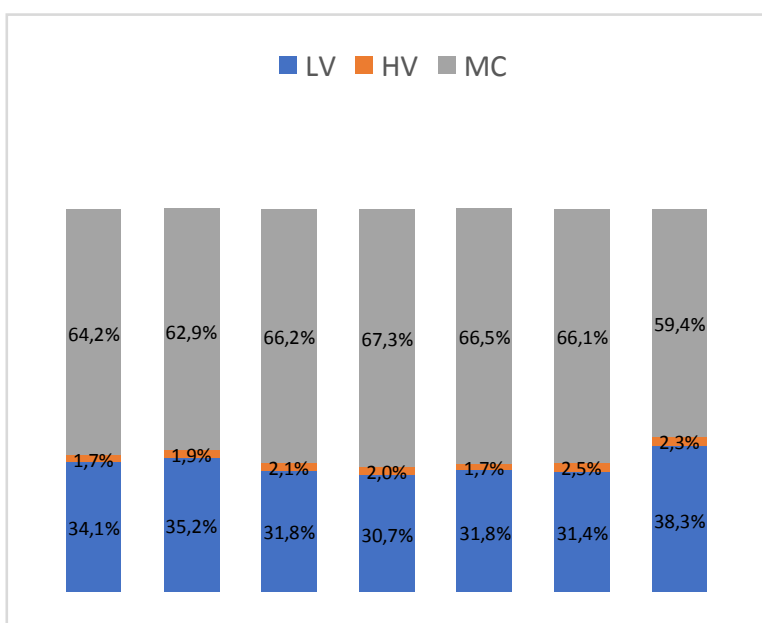

Gambar 2. Volume lalu lintasJam sibuk sore Analisis Fasilitas Penyeberangan Analisis dilakukan dengan menggunakan persamaan $\mathrm{PV}^{2}$ yaitu sebagai berikut.

Tabel 6. Analisis fasilitas penyeberangan

\begin{tabular}{|c|c|c|c|c|c|c|c|c|}
\hline $\begin{array}{l}\text { Hari } \\
\text { ke- }\end{array}$ & $\begin{array}{l}\text { Waktu } \\
\text { survei }\end{array}$ & $\begin{array}{c}P \\
\text { (org/jam) }\end{array}$ & $\begin{array}{c}\mathrm{V} \\
\text { (kend/jam) }\end{array}$ & $\begin{array}{c}\mathbf{P} \\
\text { (harian } \\
\text { rata- } \\
\text { rata) }\end{array}$ & $\begin{array}{c}\mathrm{V} \\
\text { (harian } \\
\text { rata- } \\
\text { rata) }\end{array}$ & $\begin{array}{c}\text { P total } \\
\text { (org/jam) }\end{array}$ & $\begin{array}{c}\text { V total } \\
\text { (kend/jam) }\end{array}$ & $\begin{array}{c}\text { PV } \\
2\end{array}$ \\
\hline \multirow{2}{*}{1} & siang & 13 & 6783 & \multirow{2}{*}{55,33} & \multirow{2}{*}{5288,33} & \multirow{12}{*}{69,05} & \multirow{12}{*}{5148,76} & \multirow{12}{*}{18304360} \\
\hline & sore & 153 & 9082 & & & & & \\
\hline \multirow{2}{*}{2} & siang & 32 & 5533 & \multirow{2}{*}{49,67} & \multirow{2}{*}{4711,33} & & & \\
\hline & sore & 117 & 8601 & & & & & \\
\hline \multirow{2}{*}{3} & siang & 60 & 6414 & \multirow{2}{*}{53,00} & \multirow{2}{*}{5247,33} & & & \\
\hline & sore & 99 & 9328 & & & & & \\
\hline \multirow{2}{*}{4} & siang & 50 & 6340 & \multirow{2}{*}{61,00} & \multirow{2}{*}{5070,33} & & & \\
\hline & sore & 133 & 8871 & & & & & \\
\hline \multirow{2}{*}{5} & siang & 131 & 7644 & \multirow{2}{*}{81,33} & \multirow{2}{*}{5969} & & & \\
\hline & sore & 113 & 10263 & & & & & \\
\hline \multirow[b]{2}{*}{6} & siang & 168 & 7481 & \multirow{2}{*}{119,33} & \multirow{2}{*}{5330} & & & \\
\hline & sore & 190 & 8509 & & & & & \\
\hline
\end{tabular}




\begin{tabular}{|c|c|c|c|c|c|c|c|c|}
\hline $\begin{array}{c}\text { Hari } \\
\text { ke- }\end{array}$ & $\begin{array}{c}\text { Waktu } \\
\text { survei }\end{array}$ & $\begin{array}{c}\mathbf{P} \\
\text { (org/jam) }\end{array}$ & $\begin{array}{c}\mathbf{V} \\
\text { (kend/jam) }\end{array}$ & $\begin{array}{c}\mathbf{P} \\
\text { (harian } \\
\text { rata- } \\
\text { rata) }\end{array}$ & $\begin{array}{c}\mathbf{V} \\
\text { (harian } \\
\text { rata- } \\
\text { rata) }\end{array}$ & $\begin{array}{c}\text { P total } \\
\text { (org/jam) }\end{array}$ & $\begin{array}{c}\text { V total } \\
\text { (kend/jam) }\end{array}$ & PV2 $^{2}$ \\
\hline \multirow{2}{*}{7} & siang & 58 & 6162 & 63,67 & 4425 & & & \\
\cline { 2 - 9 } & sore & 133 & 7113 & 63,5 & \\
\hline
\end{tabular}

Sumber : Hasil penelitian(2021)

$\mathrm{PV}^{2}=69,05 \times 5148,76^{2}$

$=1830435060$

Berdasarkan analisis diperoleh nilai PV2 $>2 \times 10^{8}$, dengan $\mathrm{P}=500-1000 \mathrm{org} / \mathrm{jam}$ dan $\mathrm{V}=>75$ kendaraan/jam, maka sesuai pada Pedoman Perencanaan Teknis Fasilitas Pejalan Kaki (PD 03-2017-B) jembatan penyeberangan yang tepat adalah Pelican dengan lapak tunggu.

\section{SIMPULAN}

Dari hasil analisis dan perhitungan yang telah dilakukan, maka dapat diperoleh kesimpulan sebagai berikut :

1. Tingkat efektivitas Jembatan Penyeberangan Orang (JPO) Jalan Sisingamangaraja Kota Medan ialah efektif dengan persentase tingkat efektivitas adalah $61 \%$.

2. Fasilitas penyeberangan berdasarkan jumlah penyeberang jalan dan jumlah arus lalu lintas yang melintasi ruas jalan di bawah JPO Jalan Sisingamangaraja adalah Pelican dengan lapak tunggu.

\section{DAFTAR PUSTAKA}

Departemen Pekerjaan Umum. Direktorat Jenderal Bina Marga. Direktorat Bina Teknik. 1995. Tata Cara Perencanaan Jembatan Penyeberangan Untuk Pejalan Kaki Di Perkotaan No.027/Bt/1995. Jakarta Harahap, Hariman Hakim. 2014. Analisis Karakteristik Penggunaan Jembatan Penyeberangan Di Jalan Jenderal Sudirman Kota Palembang. Jurnal Teknik Sipil dan LingkunganVol.2
No.1. Universitas Brawijaya. Malang.

Kementerian Pekerjaan Umum dan Perumahan Rakyat. 2017. Pedoman Perencanaan Teknis Fasilitas Pejalan Kaki. Jakarta.

Undang-Undang No.22 Tahun 2009 tentang Lalu Lintas dan Angkutan Jalan. 